\title{
Theoretical Study of Ability of Boron Nitride Nanocone to Oxidation of Sulfur Monoxide
}

\author{
Xuewu Zuo, ${ }^{1}$ Kourosh Behradfar, ${ }^{2}$ Jia-Bao Liu, ${ }^{3, \star}$ \\ Milad Janghorban Lariche ${ }^{4, *}$ and Meysam Najafi ${ }^{5, *}$ \\ ${ }^{1}$ Department of Common Course Teaching, Anhui Xinhua University, Hefei 230088, Anhui, P. R. China \\ ${ }^{2}$ Department of Chemical Engineering, Quchan Branch, Islamic Azad University, Quchan, Iran. \\ ${ }^{3}$ Jia-Bao Liu, School of Mathematics and Physics, Anhui Jianzhu University, Hefei 230601, P.R. China \\ ${ }^{4}$ Abadan School of Medical Sciences, Abadan, IRAN. \\ ${ }^{5}$ Medical Biology Research Center, Kermanshah University of Medical Sciences, Kermanshah 67149-67346, Iran \\ *Corresponding author: E-mail: liujiabaoad@163.com,janghorban@abadanums.ac.ir \\ and meysamnajafi2016@gmail.com
}

Received: 18-10-2017

\begin{abstract}
In recent years, the discovery of suitable catalyst to oxidation of sulfur monoxide (SO) in normal temperature is a major concern in the industry. In this study, in first step; the boron nitride nanocone (BNNC) with Ge were doped and the surface of Ge-BNNC by using of the $\mathrm{O}_{2}$ molecule were activated. In second step; oxidation of SO on surface of Ge-BNNC through the Langmuir Hinshelwood ( $\mathrm{LH}$ ) and Eley Rideal (ER) mechanisms was investigated. Calculated data reveal that surface of $\mathrm{O}_{2}$-Ge-BNNC oxide the $\mathrm{SO}$ molecule with Ge-BNNC-O-O* $+\mathrm{SO} \rightarrow \mathrm{Ge}-\mathrm{BNNC}-\mathrm{O}-\mathrm{O} *-\mathrm{SO} \rightarrow \mathrm{Ge}-\mathrm{BNNC}-\mathrm{O}^{*}$ $+\mathrm{SO}_{2}$ and $\mathrm{Ge}-\mathrm{BNNC}-\mathrm{O}^{*}+\mathrm{SO} \rightarrow \mathrm{Ge}-\mathrm{BNNC}+\mathrm{SO}_{2}$ reactions. It can be concluded, the energy barrier of $\mathrm{LH}$ mechanism to oxidation of SO on Ge-BNNC is lower than ER mechanism. Finally, the Ge-BNNC is acceptable catalyst with low price and high performance to oxidation of SO in normal temperature.
\end{abstract}

Keywords: Catalyst; nanostructure; metal adoption; oxidation reaction; adsorption energy

\section{Introduction}

Refiners, industries, mines and factories product the toxic gases that removing of produced toxic gases by oxidation reactions are important to reduce air pollution. ${ }^{1-3}$ In recent years, researchers were done various works to oxidation of the toxic gases via catalysts with high performance. ${ }^{4-6}$

In industry, catalysts containing various metals have great activity, proper performance and high sensitivity and dispersed metal catalysts were used in vital chemical reactions, generally. ${ }^{7-9}$ Previous works about oxidation of important toxic gases via metal catalysts proved that metal catalysts were expensive and they have great energy barrier and also they needed high temperature to have appropriate efficiency. ${ }^{10-12}$

In order to overcome mentioned problems and discover the novel catalyst with low price, high stability and high action in normal temperature; the nano clusters and nanostructures as catalysts of oxidation reactions of important toxic gases were used. ${ }^{13-18}$

Recently many of nanostructures because of their remarkable properties such as big surface-to-volume relationship, comfort of adopting and functionalization, high efficiency in normal temperature were used as sensor of toxic gases. ${ }^{19-21}$ Previous studies show that functionalization of nanostructures via organic groups and doping of nanostructures via suitable metal atoms can improve the physical and chemical properties of nanostructures. The functionalization and adoption of nanostructures can improve the response and sensitivity of nanostructures to toxic gases. ${ }^{22-27}$

The oxidation of sulfur monoxide (SO) as deadly gas can reduce the environmental complications, significantly. Commonly, nanostructures as catalyst can oxide the SO molecule via Langmuir-Hinshelwood (LH) and Eley-Rideal (ER) mechanisms. ${ }^{28-30}$ In previous studies, oxidation of toxic gases on metal-adopted nanostructure surfaces via LH and ER mechanisms were investigated. Results show that oxidation mechanism of toxic gases depends on the type of nanostructures and adopted metals. Results indicated that adopted-metals on the nanostructure surface can improve the rate and quality of oxidation reaction of toxic gases, significantly. ${ }^{31-33}$

In LH mechanism the oxygen molecule $\left(\mathrm{O}_{2}\right)$ and $\mathrm{SO}$ were adsorbed on surface of catalyst and also in surface of catalyst an intermediate state were formed and finally sulfur dioxide $\left(\mathrm{SO}_{2}\right)$ were separated. In ER mechanism, strai- 
ghtforward reaction between the pre-adsorbed $\mathrm{O}_{2}$ and adsorbed SO were performed. ${ }^{34-36}$

In previous studies, the potential of metal-adopted nanostructure as catalysts of toxic gases oxidation via $\mathrm{LH}$ and ER mechanisms were investigated. Results proved that metal-adopted nanostructures were acceptable catalysts with high performance and lower energy barrier. ${ }^{37-40}$ Therefore, metal-adopted nanostructures can propose the novel high performance and low price catalysts for toxic gases oxidation at normal temperature. ${ }^{41-43}$

In this study, the surface of boron nitride nanocone were adopted by $\mathrm{Ge}$ atom and the $\mathrm{SO}$ oxidation on $\mathrm{Ge}$-adopted BNNC low price as catalyst via LH and ER mechanisms were investigated by theoretical methods. The main questions that were answered in this work are: (1) How much adoption energy is needed to adoption of Ge on BNNC surface? (2) How much adsorption energy is needed to $\mathrm{O}_{2}$ and $\mathrm{SO}$ adsorption on Ge-BNNC surface? (3) Can Ge-BNNC be a low price catalyst for SO oxidation in normal temperature? (4) How much barrier and adsorption energies are needed to $\mathrm{SO}$ oxidation on Ge-BNNC surface? (5) Which mechanisms are more appropriate for $\mathrm{SO}$ oxidation on Ge-BNNC surface?

\section{1. Computational Details}

In this study the geometry optimization and frequency calculations of studied nanostructures and their complexes with $\mathrm{SO}$ and $\mathrm{O}_{2}$ were done by DFT/ M06-2X method and 6-311G (2d, 2p) basis set in GAMESS software. ${ }^{44-48}$ In this study, the unsaturated border effects by adding the hydrogen atoms to Ge-BNNC and corresponding studied complexes were avoided. The adsorption energy $\left(\mathrm{E}_{\mathrm{ad}}\right)$ values of studied molecules on Ge-BNNC surfaces were equal with difference in energies between of complexes and corresponding monomers. ${ }^{49,50}$

\section{Results and Discussions}

\section{1. The Ge Adoption of $B N N C$ and Adsorption of $\mathrm{SO}$ and $\mathrm{O}_{2}$ on Ge-BNNC Surface}

Gao et al. ${ }^{51}$ determined the reverse eccentric connectivity index of one family of pentagonal carbon nanocones and three infinite families of fullerenes based on graph analysis and computation derivation, and their results suggested the theoretical basis for material properties.

Gao et al..$^{52}$ investigated the oxidation of $\mathrm{CN}$ on surface of the Ge-CNT via the Langmuir Hinshelwood and the Eley Rideal mechanisms. Their results show that oxidation of $\mathrm{CN}$ on surface of Ge-CNT via the $\mathrm{LH}$ mechanism has lower energy barrier than ER mechanism. Their results shown that reveal that Ge-CNT is acceptable catalyst with high performance for $\mathrm{CN}$ oxidation.
Gao et al. ${ }^{53}$ by means of graph structure analysis and edge dividing technology, formulate for calculating the fifth geometric arithmetic index of bridge graph was given. They presented the fifth geometric-arithmetic index of carbon nanocones.

In previous studies, results show that adoption of BNNCs with metal atoms can modify their electrical properties, chemical activity and reaction potential, efficiently. ${ }^{22-27}$ In this study, first the structure of BNNC and Ge-BNNC were optimized and their binding distances were reported in figure 1.

In figure 1 , the $\mathrm{Ge}$ atom was adopted to $\mathrm{BNNC}$ and $\mathrm{Ge}$ atom was formed three bonds by bordering $\mathrm{C}$ atoms. Figure 1 show that, average of calculated bond lengths of $\mathrm{Ge}$ atom with three bordering $\mathrm{N}$ atoms is ca $1.91 \AA$. Calculated bond length of each $\mathrm{N}$ atom with three bordering $\mathrm{B}$ atoms is ca $1.40 \AA$. These growth in the $\mathrm{Ge}-\mathrm{N}$ rather than $\mathrm{B}-\mathrm{N}$ were interpreted by forcing of bordering $\mathrm{N}$ atoms via the $\mathrm{Ge}$ atom and so the locations of the $\mathrm{Ge}$ atom and bordering $\mathrm{N}$ atoms were perturbed toward out of the main plane.

Table 1. Obtained parameters for Ge adoption of BNNC and calculated parameters for $\mathrm{SO}$ and $\mathrm{O}_{2}$ adsorption on Ge-BNNC surface.

\begin{tabular}{lccccc}
\hline Nanoparticles & $\begin{array}{c}\Delta \mathbf{E}_{\text {ad }} \\
(\mathrm{eV})\end{array}$ & $\begin{array}{c}\Delta \mathbf{H}_{\mathrm{ad}} \\
(\mathrm{eV})\end{array}$ & $\begin{array}{c}\Delta \mathbf{G}_{\mathrm{ad}} \\
(\mathrm{eV})\end{array}$ & $\mathbf{q}(\mathrm{e})$ & $\begin{array}{c}\mathrm{E}_{\mathrm{HLG}} \\
(\mathrm{eV})\end{array}$ \\
\hline Ge-BNNC & -1.22 & -1.18 & -0.75 & 0.64 & 2.35 \\
Ge-BNNC-SO & -0.43 & -0.37 & 0.32 & 0.11 & 2.36 \\
Ge-BNNC-O $_{2}$ & -1.32 & -1.28 & -0.64 & 0.79 & 2.98 \\
\hline
\end{tabular}

The adoption energy $\left(\Delta \mathrm{E}_{\mathrm{ad}}\right)$, enthalpy $\left(\Delta \mathrm{H}_{\mathrm{ad}}\right)$, Gibes free energy $\left(\Delta \mathrm{G}_{\mathrm{ad}}\right)$ and energy of HOMO-LUMO gap $\left(\mathrm{E}_{\mathrm{HLG}}\right)$ of $\mathrm{Ge}-\mathrm{BNNC}$ were calculated. The transferred charge (q) between Ge atom and BNNC surface were calculated and obtained results reported in table 1. Results shown that, the calculated $\Delta \mathrm{E}_{\mathrm{ad}}, \Delta \mathrm{H}_{\mathrm{ad}}, \Delta \mathrm{G}_{\mathrm{ad}}, \mathrm{E}_{\mathrm{HLG}}$ and q values of Ge-BNNC were $-1.22,-1.18,-0.75,2.35 \mathrm{eV}$ and 0.64 electron, respectively. The large energy and charge transfer values were proved that in Ge-BNNC there are three strong covalent bonds between $\mathrm{Ge}$ atom and bordering $\mathrm{N}$ atoms.

The study of $\mathrm{SO}$ and $\mathrm{O}_{2}$ adsorption on Ge-BNNC surface has high important in order to investigation of $\mathrm{SO}$ oxidation. In this step the adsorption ability of $\mathrm{SO}$ and $\mathrm{O}_{2}$ on Ge-BNNC surface were investigated and the most stable Ge-BNNC-SO and Ge-BNNC- ${ }_{2}$ complexes from the energy viewpoint were shown in figure 1.

Structure of Ge-BNNC-SO complex in figure 1 show that the distance between $\mathrm{SO}$ and Ge-BNNC was $3.53 \AA$ A. The adsorption parameters in table 1 show that, the calculated $\Delta \mathrm{E}_{\mathrm{ad}}, \Delta \mathrm{H}_{\mathrm{ad}}, \Delta \mathrm{G}_{\mathrm{ad}}$ values of Ge-BNNC-SO were $-0.43,-0.37$ and $0.32 \mathrm{eV}$, respectively. The calculated q value for interaction between $\mathrm{SO}$ and Ge-BNNC is ca 0.11 electron. Additionally, $\mathrm{E}_{\mathrm{HLG}}$ parameter in order to determination of changing in electronic properties of $\mathrm{Ge}-\mathrm{BNNC}$ after SO adsorption was calculated and obtained results reported in table 1. 


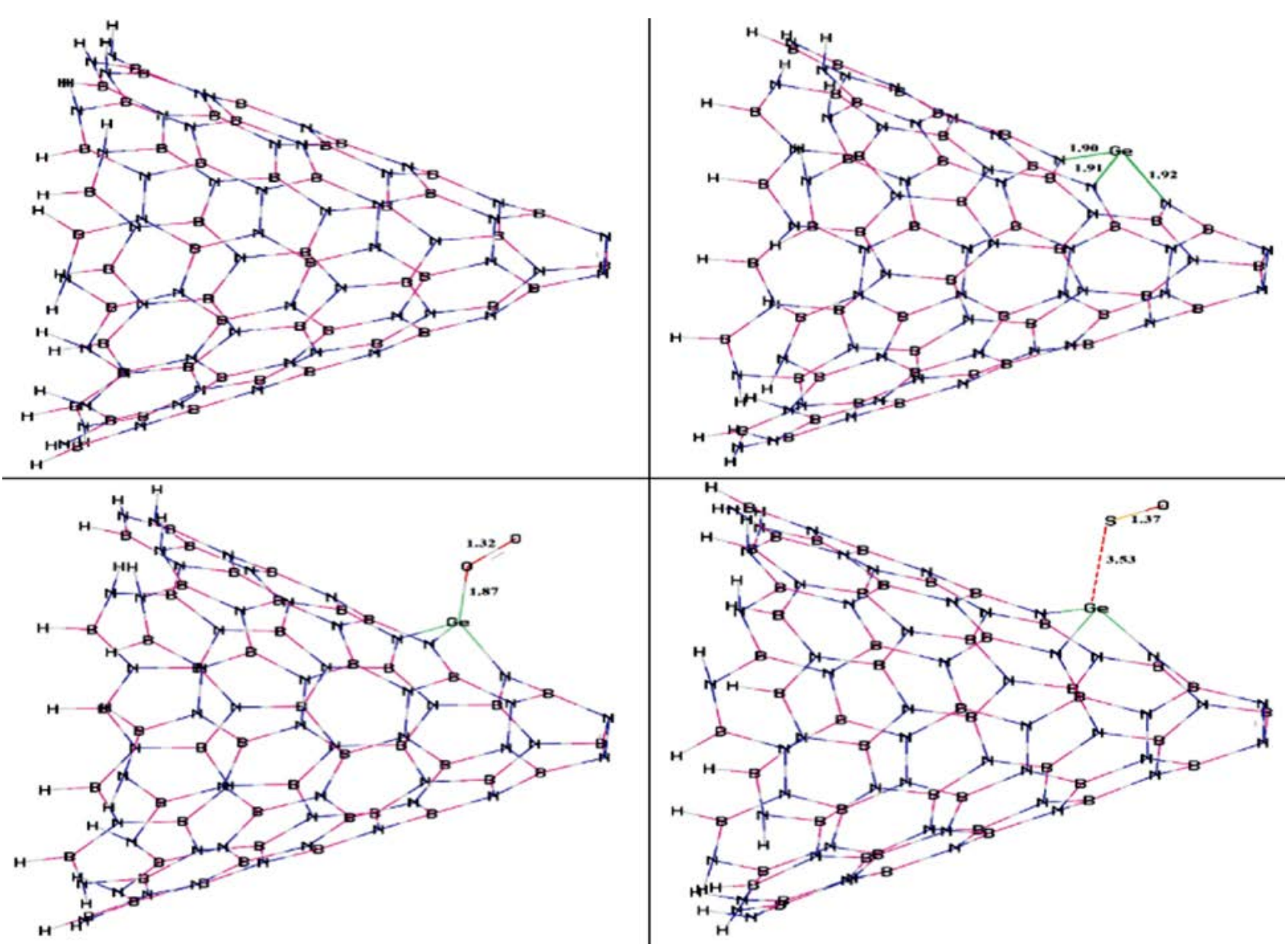

Figure 1. Structures of BNNC, Ge-BNNC, Ge-BNNC-O $\mathrm{O}_{2}$ and Ge-BNNC-SO (bond distances $(\AA)$ ).

Results indicated that Ge-BNNC and Ge-BNNC-SO have same $\mathrm{E}_{\mathrm{HLG}}$ values. The low charge transfer from $\mathrm{Ge}-$ -BNNC to $\mathrm{SO}$ show that $\mathrm{SO}$ adsorption on Ge-BNNC surface cannot modify the activity of Ge-BNNC, significantly. The low $\Delta \mathrm{E}_{\mathrm{ad}}$ and $\Delta \mathrm{H}_{\mathrm{ad}}$ values and positive $\Delta \mathrm{G}_{\mathrm{ad}}$ values of Ge-BNNC-SO show that interactions SO with Ge-BNNC were weakly and $\mathrm{SO}$ adsorption on Ge-BNNC surface was impossible from energy viewpoint.

As seen in figure 1, in Ge-BNNC- $\mathrm{O}_{2}$ the distance between of $\mathrm{O}_{2}$ and Ge-BNNC was $1.87 \AA$. The adsorption parameters in table 1 show that, the calculated $\Delta \mathrm{E}_{\mathrm{ad}}, \Delta \mathrm{H}_{\mathrm{ad}}$, $\Delta \mathrm{G}_{\mathrm{ad}}$ values of Ge-BNNC- $\mathrm{O}_{2}$ were $-1.32,-1.28$ and -0.64 $\mathrm{eV}$, respectively. The large calculated $\Delta \mathrm{E}_{\mathrm{ad}}, \Delta \mathrm{H}_{\mathrm{ad}}$ and $\Delta \mathrm{G}_{\mathrm{ad}}$ values confirm that $\mathrm{O}_{2}$ and $\mathrm{Ge}-\mathrm{BNNC}$ have appropriate chemical interactions.

The $\mathrm{O}_{2}$ bond length in Ge-BNNC- $\mathrm{O}_{2}$ is $1.32 \AA$ that is longer than bond length in single $\mathrm{O}_{2}$ ca $0.11 \AA$. Results show, when Ge-BNNC- $\mathrm{O}_{2}$ is formed the $\mathrm{O}_{2}$ bond length is elongated and $\mathrm{O}_{2}$ on Ge-BNNC surface is activated. The obtained q value of chemical interaction between $\mathrm{O}_{2}$ and $\mathrm{Ge}-\mathrm{BNNC}$ is ca 0.79 electron. Calculated $\mathrm{E}_{\mathrm{HLG}}$ value show that $\mathrm{Ge}-\mathrm{BNNC}-\mathrm{O}_{2}$ has higher $\mathrm{E}_{\mathrm{HLG}}$ values rather than $\mathrm{Ge}$ -BNNC ca $0.63 \mathrm{eV}$. Therefore results show that $\mathrm{O}_{2}$ adsorption on Ge-BNNC surface can modify the chemical structure of Ge-BNNC and $\mathrm{O}_{2}$ adsorption improve the chemical activity of Ge- BNNC, efficiently.

In finally, results in table 1 show that $\mathrm{O}_{2}$ adsorption on Ge-BNNC surface improve the chemical properties of Ge-BNNC because of large $\mathrm{q}, \Delta \mathrm{E}_{\mathrm{ad}}$ and $\Delta \mathrm{H}_{\mathrm{ad}}$ values. Also results confirm that when the equal amount of $\mathrm{SO}$ and $\mathrm{O}_{2}$ molecules were in nearby of Ge-BNNC structure the Ge-BNNC surface covered by adsorbed $\mathrm{O}_{2}$ molecule exactly. So the Ge-BNNC- $\mathrm{O}_{2}$ formation can be considered as first step in $\mathrm{SO}$ oxidation process.

\section{2. SO Oxidation on Activated Ge-BNNC Surface via ER and LH Mechanisms}

As illustrious in introduction the ER and LH were possible mechanisms to SO oxidation on surface of nanostructures. In ER mechanism, SO molecule was neared to surface of activated Ge-BNNC, but in $\mathrm{LH}$ mechanism first $\mathrm{SO}$ and $\mathrm{O}_{2}$ groups adsorbed and then oxidation done on Ge-BNNC surface. In previous studies, the ER and LH mechanisms for toxic gas oxidation on metal-adopted nanostructures were investigated and results show that metal-adopted nanostructures were acceptable catalyst to toxic gas oxidation. ${ }^{28-36}$ 
In this section the potential of Ge-BNNC surface for $\mathrm{SO}$ oxidation were investigated and energy path ways for SO oxidation in both ER and LH mechanisms were exanimated. The SO oxidation path ways on Ge-BNNC surface in figures 2 and 3 were shown. The calculated activation energies $\left(\mathrm{E}_{\mathrm{ac}}\right)$ and thermodynamic indexes $\left(\Delta \mathrm{E}_{\mathrm{ad}}, \Delta \mathrm{H}_{\mathrm{ad}}\right.$ and $\left.\Delta \mathrm{G}_{\mathrm{ad}}\right)$ of studied path ways were reported in table 2 .

Results in table 2 show that, energy barrier of SO oxidation on $\mathrm{O}_{2}$ activated Ge-BNNC surface via $\mathrm{LH}$ mechanism was lower than corresponding value of ER mechanism. Therefore, the LH mechanism were considered in two following reactions; first reaction is Ge-BNNC-

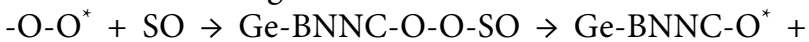
$\mathrm{SO}_{2}$, and second reaction is Ge-BNNC-O ${ }^{*}+\mathrm{SO} \rightarrow \mathrm{Ge}-\mathrm{B}-$ $\mathrm{NNC}+\mathrm{SO}_{2}$. The important structures in path way of two above reactions were geometry optimized and corresponding structures involving the initial state (IS), final state (P) and transition state (TS) structures were shown in figures 2 and 3.

In first reaction $\left(\mathrm{Ge}-\mathrm{BNNC}-\mathrm{O}-\mathrm{O}^{*}+\mathrm{SO} \rightarrow \mathrm{Ge}-\mathrm{BNN}-\right.$ $\mathrm{C}-\mathrm{O}-\mathrm{O}^{*}-\mathrm{SO} \rightarrow \mathrm{Ge}-\mathrm{BNNC}-\mathrm{O}^{*}+\mathrm{SO}_{2}$ ) the Ge-BNNC-O-O ${ }^{*}$ $\mathrm{SO}, \mathrm{Ge}-\mathrm{BNNC}-\mathrm{O}^{*}$ and Ge-BNNC-O-O* were TS, P and IS structures, respectively (structures were shown in figure 2). Calculated results in table 2 show that, $\mathrm{E}_{\mathrm{ac}}, \Delta \mathrm{E}_{\mathrm{ad}}, \Delta \mathrm{H}_{\mathrm{ad}}$ and $\Delta \mathrm{G}_{\mathrm{ad}}$ values of first reaction were $0.85,-3.43,-3.37$ and $-3.28 \mathrm{eV}$, respectively.

Figure 2 show that in IS structure the $\mathrm{SO}$ was neared to $\mathrm{Ge}-\mathrm{BNNC}-\mathrm{O}-\mathrm{O}^{*}$ and the $\mathrm{O}-\mathrm{O}$ was lengthened from 1.32 to $1.48 \AA$ and in IS structure the distance between SO and $\mathrm{O}_{2}$ was $2.99 \AA$. Figure 2 indicated that in TS structure the Ge-BNNC-O-O ${ }^{*}-\mathrm{SO}$ was designed and the $\mathrm{O}-\mathrm{O}^{*}$ and $\mathrm{O}^{*}-\mathrm{S}$ were 1.59 and $1.44 \AA$, respectively. Therefore results in first reaction show that a $\mathrm{SO}_{2}$ molecule was formed at room temperature because the interaction of Ge-BNNC$-\mathrm{O}^{*}$ with $\mathrm{SO}_{2}$ was weakly.

In second reaction $\left(\mathrm{Ge}-\mathrm{BNNC}-\mathrm{O}^{*}+\mathrm{SO} \rightarrow \mathrm{Ge}-\mathrm{B}\right.$ $\mathrm{NNC}+\mathrm{SO}_{2}$ ) the Ge-BNNC-O*-SO, Ge-BNNC and Ge-BNNC-O ${ }^{*}$ were TS, P and IS structures, respectively (structures were shown in figure 3). Calculated results in table 2 show that, $\mathrm{E}_{\mathrm{ac}}, \Delta \mathrm{E}_{\mathrm{ad}}, \Delta \mathrm{H}_{\mathrm{ad}}$ and $\Delta \mathrm{G}_{\mathrm{ad}}$ values of second reaction were $0.18,-2.99,-2.92$ and $-2.84 \mathrm{eV}$, respectively.

Figure 3 show that in IS structure the SO was neared to $\mathrm{Ge}-\mathrm{BNNC}-\mathrm{O}^{*}$ and the $\mathrm{O}^{*}-\mathrm{S}$ and $\mathrm{Ge}-\mathrm{O}^{*}$ bonds were 2.95 and $1.80 \AA$, respectively. Figure 3 indicated that in TS structure the Ge-BNNC-O ${ }^{*}-\mathrm{SO}$ was designed and the $\mathrm{Ge}-\mathrm{O}^{*}$

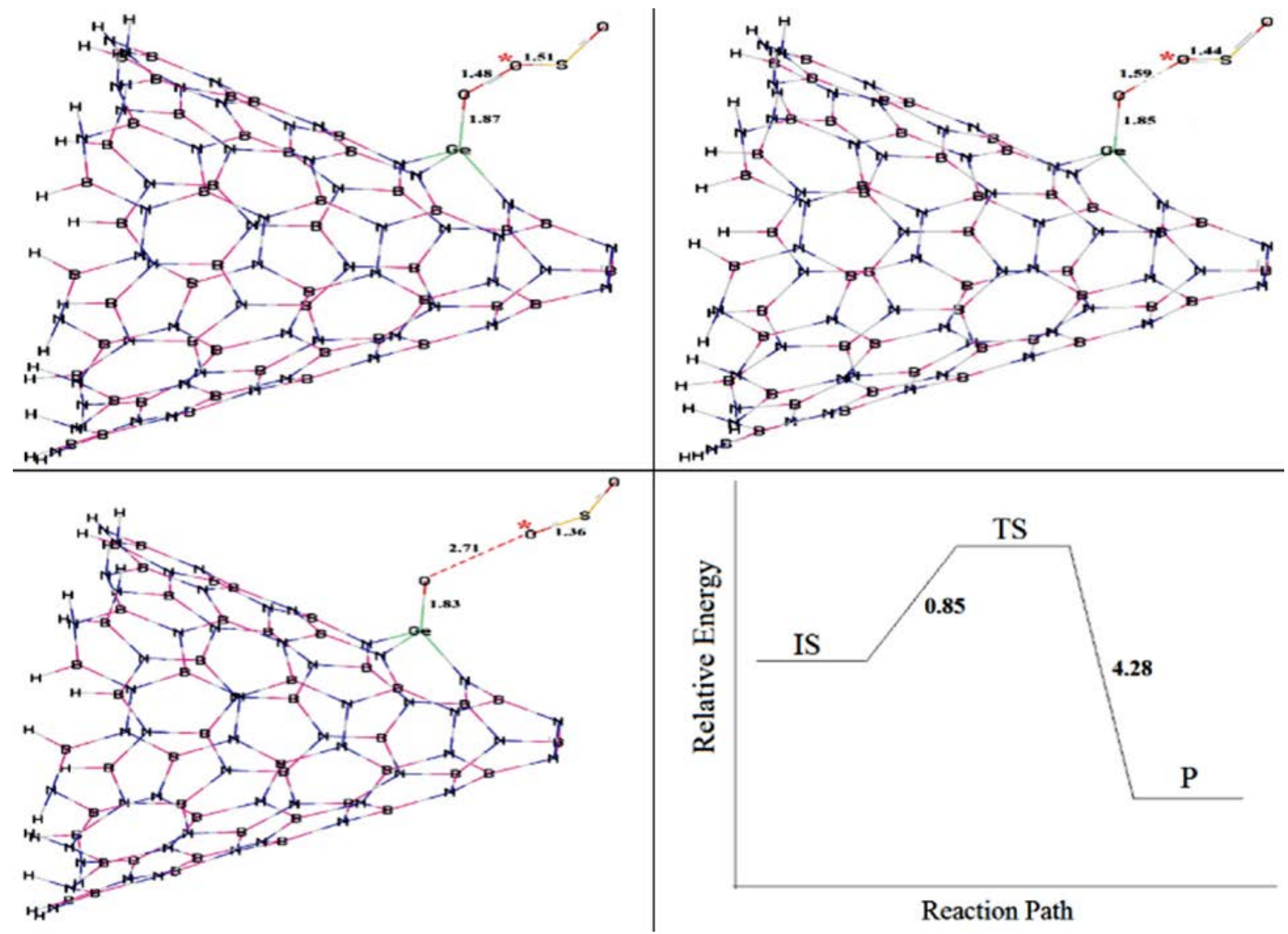

Figure 2. Plan of Ge-BNNC-O-O ${ }^{*}+\mathrm{SO} \rightarrow \mathrm{Ge}-\mathrm{BNNC}-\mathrm{O}+\mathrm{SO}_{2}$ reaction (Bond distances $(\AA)$ and relative energies $(\mathrm{eV})$ ). 
Table 2. Obtained parameters for Ge-BNNC-O-O ${ }^{*}+\mathrm{SO} \rightarrow \mathrm{Ge}-\mathrm{BNNC}-\mathrm{O}+\mathrm{SO}_{2}$ and Ge-BNNC-O ${ }^{*}+\mathrm{SO} \rightarrow$ $\mathrm{Ge}-\mathrm{BNNC}+\mathrm{SO}_{2}$ reactions.

\begin{tabular}{lcccc}
\hline Reactions & $\mathbf{E}_{\mathrm{ac}}(\mathrm{eV})$ & $\Delta \mathrm{E}_{\mathrm{ad}}(\mathrm{eV})$ & $\Delta \mathrm{H}_{\mathrm{ad}}(\mathrm{eV})$ & $\Delta \mathrm{G}_{\mathrm{ad}}(\mathrm{eV})$ \\
\hline $\mathrm{Ge}^{-B N N C-O}-\mathbf{O}^{*}+\mathrm{SO} \rightarrow \mathrm{Ge}-\mathrm{BNNC}-\mathrm{O}+\mathrm{SO}_{2}$ & 0.85 & -3.43 & -3.37 & -3.28 \\
$\mathrm{Ge}^{-B N N C-O^{*}}+\mathrm{SO} \rightarrow \mathrm{Ge}-\mathrm{BNNC}+\mathrm{SO}_{2}$ & 0.18 & -2.99 & -2.92 & -2.84 \\
\hline
\end{tabular}
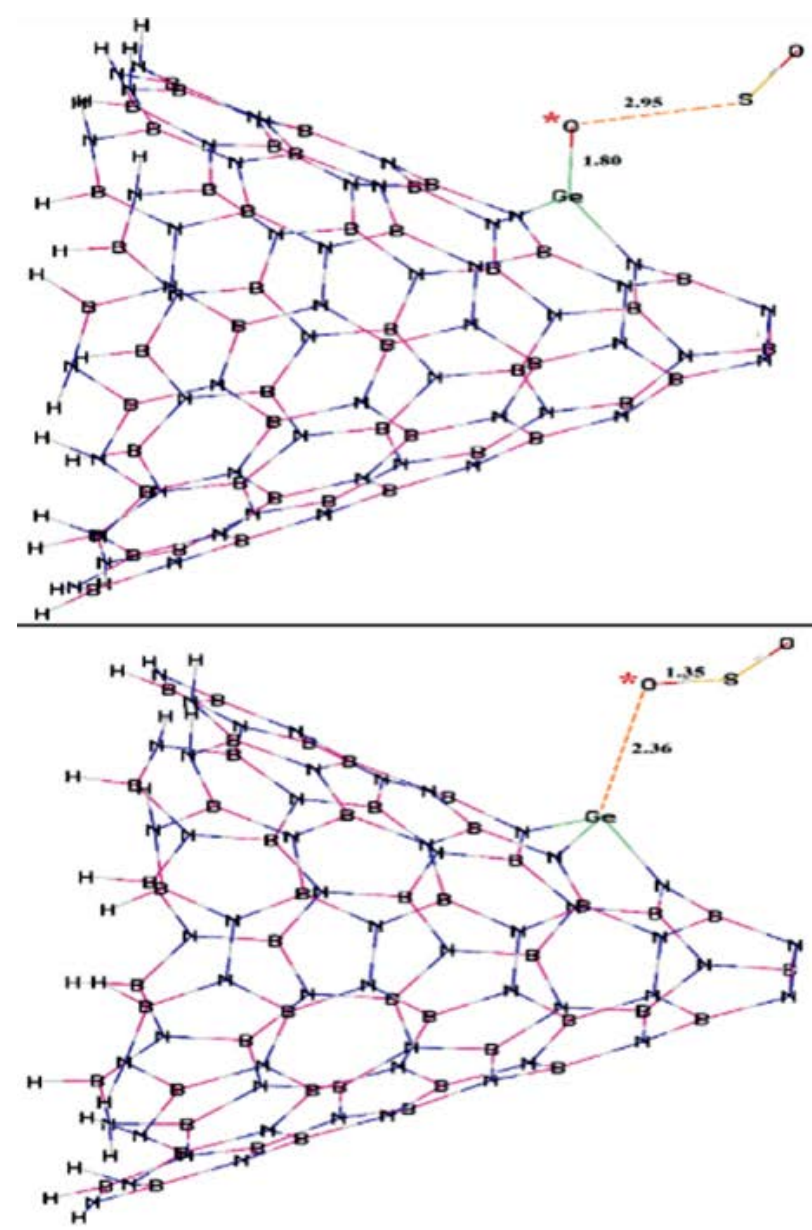

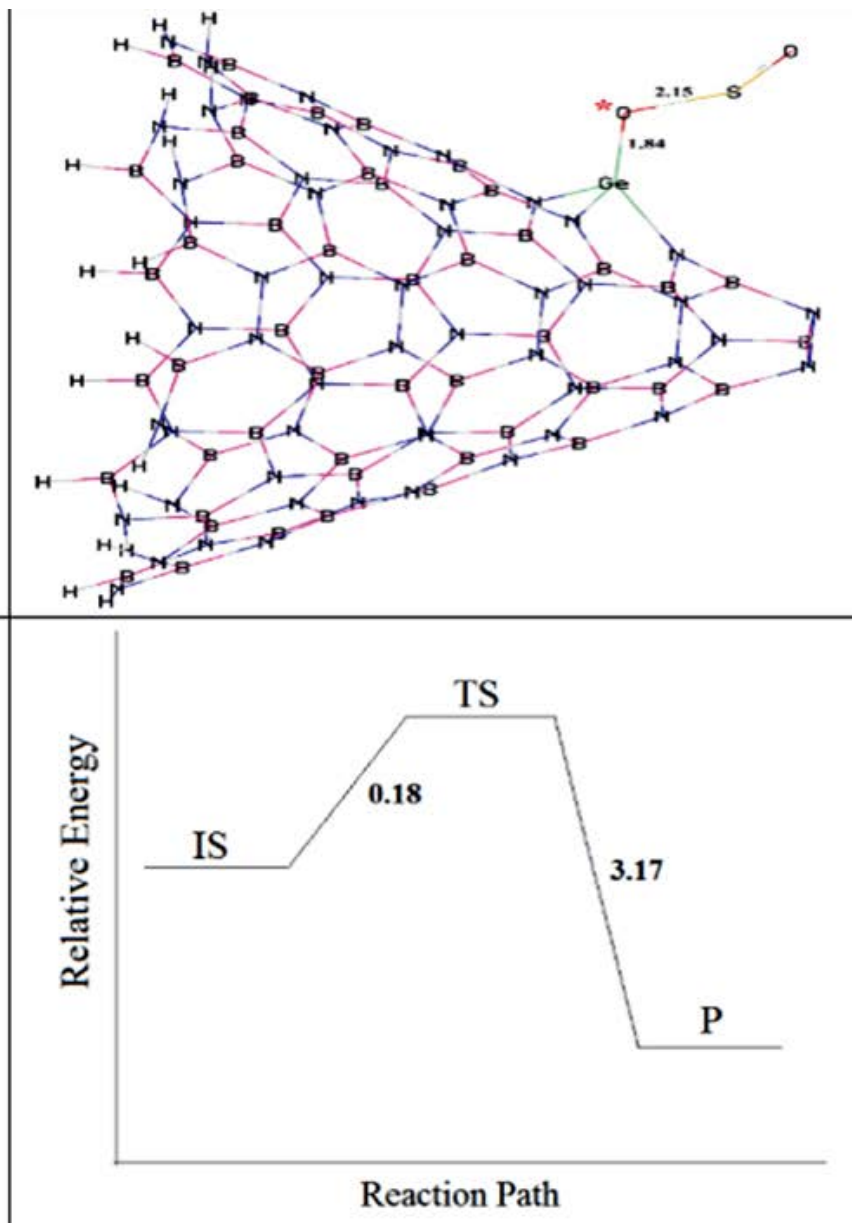

Figure 3. Plan of Ge-BNNC-O ${ }^{*}+\mathrm{SO} \rightarrow \mathrm{Ge}-\mathrm{BNNC}+\mathrm{SO}_{2}$ reaction (Bond distances $(\AA)$ and relative energies $(\mathrm{eV})$ ).

and $\mathrm{O}^{*}-\mathrm{S}$ were 1.84 and $2.15 \AA$, respectively. Therefore results show that in second reaction a $\mathrm{SO}_{2}$ molecule was formed at room temperature because the interaction of Ge-B$\mathrm{NNC}$ with $\mathrm{SO}_{2}$ was weakly.

That is remarkable that two investigated reactions $\left(\mathrm{Ge}-\mathrm{BNNC}-\mathrm{O}-\mathrm{O}^{*}+\mathrm{SO} \rightarrow \mathrm{Ge}-\mathrm{BNNC}-\mathrm{O}-\mathrm{O}-\mathrm{SO} \rightarrow \mathrm{Ge}-\mathrm{B}-\right.$ $\mathrm{NNC}-\mathrm{O}^{*}+\mathrm{SO}_{2}$ and $\mathrm{Ge}-\mathrm{BNNC}-\mathrm{O}^{*}+\mathrm{SO} \rightarrow \mathrm{Ge}-\mathrm{BNNC}+$ $\mathrm{SO}_{2}$ ) in figures 2 and 3 were exothermic. The calculated $\Delta \mathrm{G}_{\mathrm{ad}}$ in table 2 propose that the two studied reactions were negative in normal temperature and so the $\mathrm{SO}$ oxidation via Ge-BNNC-O* and Ge-BNNC-O-O* was favorable from thermodynamic view point. Finally results show that, Ge-BNNC can be remarkable catalyst for SO oxidation via LH mechanism with high efficiency due to low barrier energy in normal temperature.

\section{Conclusion}

The DFT method used to SO oxidation on activated Ge-BNNC surface via LH and ER mechanisms. Results indicated that Ge-BNNC can be an efficient catalyst to $\mathrm{SO}$ oxidation with low cost in normal temperature. Results show that $\mathrm{O}_{2}$ adsorption on $\mathrm{Ge}-\mathrm{BNNC}$ surface cause greater effects on properties of Ge-BNNC. Results show that $\Delta \mathrm{E}_{\mathrm{ad}}$ and $\mathrm{q}$ values of $\mathrm{Ge}-\mathrm{BNNC}-\mathrm{O}_{2}$ were higher than Ge-BNNC-SO. Results show when the $\mathrm{SO}$ and $\mathrm{O}_{2}$ reached to Ge-BNNC the Ge-BNNC surface surround with $\mathrm{O}_{2}$, concurrently. Results show that $\mathrm{SO}$ oxidation on Ge-BNNC surface via the LH mechanism has lower energy barrier than ER mechanism. Finally, results propose that $\mathrm{O}_{2}$ activated $\mathrm{Ge}-\mathrm{BNNC}$ can be a novel catalyst 
to SO oxidation with high efficient and low price in normal temperature.

\section{Acknowledgment}

The authors would like to thank all chemistry teachers for scientific supports.

\section{References}

1. A. Kiani, P. Haratipour, M. Ahmadi, R. Zare-Dorabei, A. Mahmoodi, J. Water Supply. Res. 2017, 66, 239-248.

2. Z. Parsaee, P. Haratipour, M. Janghorban Lariche, A. Vojood, Ultrason. Sonochem. 2018, 41, 337-349.

DOI:10.1016/j.ultsonch.2017.09.054

3. P. Haratipour, A. Baghban, A. H. Mohammadi, S. H. Hosseini Nazhad, A. Bahadori, J. Mol. Liq. 2017, 242, 146-159.

DOI:10.1016/j.molliq.2017.06.123

4. M. H. Doranehgard, H. Samadyar, M. Mesbah, P. Haratipour, S Samiezade, Fuel, 2017, 202, 29-35.

DOI:10.1016/j.fuel.2017.04.014

5. A. Baghban, J. Sasanipour, P. Haratipour, M. Alizad, M. Vafaee Ayouri, Chem. Eng. Res. Des. 2017, 126, 67-75.

DOI:10.1016/j.cherd.2017.08.007

6. W. Gao, P. Haratipour, M. R. R. Kahkha, A. Tahvili, Ultrason. Sonochem. 2018, 44, 152-161.

DOI:10.1016/j.ultsonch.2018.02.020

7. H. J. Freund, G. Meijer, M. Scheffler, Angew. Chem. 2011, 50, 10064-10094. DOI:10.1002/anie.201101378

8. R. S. Johnson, A. DeLaRiva, V. Ashbacher, Phys. Chem. Chem. Phys. 2013, 15, 7768-7776. DOI:10.1039/c3cp00126a

9. H. Y. Su, M. M. Yang, X. H. Bao, W. X. Li, J. Phys. Chem. C 2008, 112, 17303-17310. DOI:10.1021/jp803400p

10. M. S. Chen, Y. Cai, Z. Yan, Surf. Sci. 2007, 601, 5326-5331. DOI:10.1016/j.susc.2007.08.019

11. S. Piccinin, M. Stamatakis, ACS Catal. 2014, 4, 2143-2152. DOI:10.1021/cs500377j

12. W. Liu, Y. Zhu, J. Lian, Q. Jiang, J. Phys. Chem. C 2007, 111, 1005-1009. DOI:10.1021/jp0661488

13. D. J. Liu, J. Phys. Chem. C 2007, 111, 14698-14706. DOI:10.1021/jp071944e

14. W. T. Wallace, R. L. Whetten, J. Am. Chem. Soc. 2002, 124, 7499-7505. DOI:10.1021/ja0175439

15. C. Chang, C. Cheng, C. Wei, J. Chem. Phys. 2008, 128, 124710-124710. DOI:10.1063/1.2841364

16. J. Du, G. Wu, J. Wang, J. Phys. Chem. A 2010, 114, 1050810514. DOI:10.1021/jp106321s

17. Sharifian S, Harasek M, Haddadi B, Chem. Prod. Process Mod. 2016, 11, 67-72.

18. Sharifian S, Miltner M, Harasek M, Chem. Eng. Trans. 2016, $52,565-570$

19. Sharifian S, Harasek M, Chem. Eng. Trans. 2015, 45, 409-414.

20. Sharifian S, Harasek M, Chem. Eng. Trans. 2015, 45, 10031008 .
21. L. Ci, Z. Xu, L. Wang, W. Gao, F. Ding, Nano Res. 2008, 1, 116-122. DOI:10.1007/s12274-008-8020-9

22. C. Lee, X. Wei, J. W. Kysar, J. Hone, Science 2008, 321, 385 388. DOI:10.1126/science.1157996

23. K. S. Novoselov, A. K. Geim, S. Morozov, Science 2004, 306, 666-669. DOI:10.1126/science.1102896

24. A. K. Geim, K. S. Novoselov, Nat. Mater. 2007, 6, 183-191. DOI:10.1038/nmat1849

25. S. Morozov, K. Novoselov, M. KatGeelson, Phys. Rev. Lett. 2008, 100, 016602. DOI:10.1103/PhysRevLett.100.016602

26. A. K. Geim, Science 324, 2009, 1530-1534. DOI:10.1126/science.1158877

27. K. R. Ratinac, W. Yang, S. P. Ringer, F. Braet, Environ. Sci. Technol. 2010, 44, 1167-1176. DOI:10.1021/es902659d

28. A. Hornes, A. B. Hungria, J. Am. Chem. Soc. 2010, 132, 34-37. DOI: $10.1021 /$ ja9089846

29. X. Hu, Y. Wu, Z. Zhang, J. Mater. Chem. 2012, 22, 1519815205. DOI:10.1039/c2jm33490a

30. Y. Tang, X. Dai, Z. Yang, Z. Liu, L. Pan, D. Ma, Z. Lu, Carbon 2014, 71, 139-143. DOI:10.1016/j.carbon.2014.01.022

31. Y. Li, Z. Zhou, G. Yu, W. Chen, Z. Chen, J. Phys. Chem. C 2010, 114, 6250-6255. DOI:10.1021/jp911535v

32. E. H. Song, Z. Wen, Q. Jiang, J. Phys. Chem. C 2011, 115, 3678-3683. DOI:10.1021/jp108978c

33. Y. Tang, Z. Yang, X. Dai, Phys. Chem. Chem. Phys. 2012, 14, 16566-16569. DOI:10.1039/c2cp41441d

34. Y. Tang, Z. Liu, X. Dai, Z. Yang, W. Chen, Z. Lu, Appl. Surf. Sci. 2014, 308, 402-407. DOI:10.1016/j.apsusc.2014.04.189

35. S. Lin, X. Ye, J. Huang, Phys. Chem. Chem. Phys. 2015, 17, 888-893. DOI:10.1039/C4CP05007J

36. S. A. Taw fi k, X.Y. Cui, D.J. Carter, C. Stampfl, Phys. Chem. Chem. Phys. 2015, 17, 62-69.

37. A .G. Davies, Organotin Chemistry, 2nd edition, Wiley-VCH, Weinheim, 2004. DOI:10.1002/3527601899

38. H. Song, L. Zhang, C. He, Y. Qu, Y. Tian, Y. Lv, J. Mater. Chem. 2011, 21, 5972-5975. DOI:10.1039/c0jm04331a

39. Q. Zhou, C. Wang, Z. Fu, Y. Tang, H. Zhang, Comput. Mater. Sci. 2014, 83, 398-402.

DOI:10.1016/j.commatsci.2013.11.036

40. A.V. Krasheninnikov, P.O. Lehtinen, A.S. Foster, Phys. Rev. Lett. 2009, 102, 400-430.

DOI:10.1103/PhysRevLett.102.126807

41. F. Li, J. Zhao, Z. Chen, J. Phys. Chem. C 2012, 116, 2507-2514. DOI:10.1021/jp209572d

42. X. Wang, X. Li, L. Zhang, Y. Yoon, P.K. Weber, Science 2009, 324, 768-771. DOI:10.1126/science.1170335

43. A. L. M. Reddy, A. Srivastava, S.R. Gowda, H. Gullapalli, ACS Nano 2010, 4, 6337-6342. DOI:10.1021/nn101926g

44. Y. Zhao, D.G. Truhlar, Theor. Chem. Acc. 2008, 120, 215-241. DOI:10.1007/s00214-007-0310-x

45. J. Andzelm, C. Kolmel, J. Chem. Phys. 1995, 103, 9312-9320. DOI: $10.1063 / 1.469990$

46. L. H. Gan, J. Q. Zhao, Physica E 2009, 41, 1249-1252. DOI:10.1016/j.physe.2009.02.014

47. S. F. Boys, F. Bernardi, Mol. Phys. 1970, 19, 553-566. DOI:10.1080/00268977000101561 
48. L. Ma, J. M. Zhang, K. W. Xu, V. Ji, Appl. Surf. Sci. 2015, 343, 121-127. DOI:10.1016/j.apsusc.2015.03.068

49. T. Zhang, Q. Xue, M. Shan, Z. Jiao, J. Phys. Chem. C 2012, 116, 19918-19924. DOI:10.1021/jp3073359

50. M. Wu, C. Cao, J. Jiang, J. Phys. 2010, 12, 063020-063024.

51. W. Gao, M. R. Farahani, J. Nanotechno. 2016, 2016, 1-6.
52. W. Gao, S. M. Abrishamifar, G. E. Rajaei, R. Razavi, M. Najafi, Chem. Phys. Lett. 2018, 695, 44-50.

DOI:10.1016/j.cplett.2018.01.056

53. W. Gao, W. F. Wang, J. Differ. Equations Appl. 2017, 23, 100109. DOI:10.1080/10236198.2016.1197214

\section{Povzetek}

V zadnjih letih se industrija veliko ukvarja z razvojem učinkovitih in poceni katalizatorjev za oksidacijo žveplovega monoksida (SO) pri normalni temperaturi. S tem namenom smo preučevali nanostožec borovega nitrida (BNNC) dopiranega z Ge, čigar površino smo aktivirali z molekulo $\mathrm{O}_{2}$. Nato smo z uporabo Langmuir Hinshelwood (LH) in Eley Rideal (ER) mehanizmov raziskali oksidacijo SO na aktivirani površini Ge-BNNC. Rezultati kažejo, da tako aktivirana površina Ge-BNNC oksidira molekulo SO ter da ta proces lahko opišemo z zaporedjem reakcij Ge-BNNC-OO $*+\mathrm{SO} \rightarrow$ Ge-BNNC-OO ${ }^{*}-\mathrm{SO} \rightarrow \mathrm{Ge}-\mathrm{BNNC}-\mathrm{O}^{*}+\mathrm{SO} 2$ in Ge-BNNC-O ${ }^{*}+\mathrm{SO} \rightarrow \mathrm{Ge}-\mathrm{BNNC}+\mathrm{SO}_{2}$. Izkazalo se je, da oksidacija SO na aktivirani površini Ge-BNNC pri uporabi LH mehanizma poteka pri nižji energetski barieri kot pri ER mehanizmu. Izračunani parametri kažejo, da je aktiviran Ge-BNNC sprejemljiv katalizator z nizko ceno in visoko zmogljivostjo za oksidacijo SO pri normalni temperaturi. 